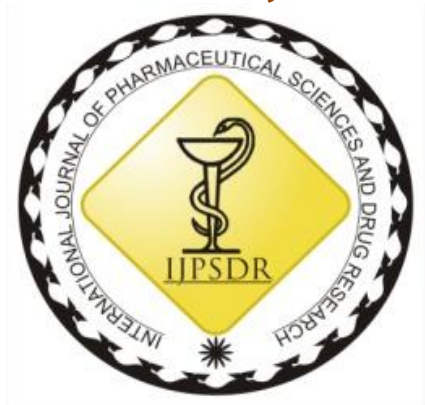

ISSN: 0975-248X

Research Article CODEN (USA): IJPSPP

(cc) BY-NC-SA

\title{
Self Nanoemulsifying Drug Delivery System of Candesartan Cilexetil with Improved Bioavailability
}

\author{
J. Venkateswara Rao*, T. Rama Mohan Reddy \\ Mewar University, NH-79, Gangrar, Chhitorgarh-312901, Rajasthan, India
}

Copyright (C) 2018 J. Venkateswara Rao et al. This is an open access article distributed under the terms of the Creative Commons Attribution-NonCommercial-ShareAlike 4.0 International License which allows others to remix, tweak, and build upon the work noncommercially, as long as the author is credited and the new creations are licensed under the identical terms.

\begin{abstract}
Candesartan is an angiotensin II receptor blocker with inherent low bioavailability. The present studies entail the optimization and evaluation of self- nanoemulsifying drug delivery system (SNEDDS) of Candesartan in order to enhance its oral bioavailability. For this Capryol 90, Captex 500, Labrasol were used as oil, surfactant and co surfactant respectively. FTIR studies revealed no interaction among the drug and polymers used in the formulation. Based on the physicochemical parameters and in-vitro dissolution studies, F17 prepared with Smix (Surfactant: Co-surfactant) of 3:1 and Oil:Smix of 6:4, was found to be an optimum one. The formulation F17 was found to release $99.12 \pm 5.10 \%$ drug at the end of one hour and scanning electron microscopic analysis showed nanosized particles. The droplet size of the optimized formulation was found to be $51.7 \mathrm{~nm} \& \mathrm{Z}$-Average of 59.2 $\mathrm{nm}$. The zeta potential of the optimized formulation (F17) was found to be $-15.5 \mathrm{mV}$. The formulations were also found to be stable over a period of 6 months of testing. From in vivo bioavailability studies $\mathrm{C}_{\max }$ of the SNEDDS $35.2 \pm 0.02 \mathrm{ng} / \mathrm{ml}$ was significant $(p<0.05)$ as compared to the pure drug suspension formulation $25.1 \pm$ $0.03 \mathrm{ng} / \mathrm{ml}$. $\mathrm{T}_{\max }$ of both SNEDDS formulation and pure drug suspension was $1.00 \pm 0.03 \mathrm{~h}$ and $2.00 \pm 0.01 \mathrm{~h}$, respectively. AUC is an important parameter in evaluating bioavailability of drug from dosage form, $\mathrm{AUC}_{0-\infty}$ infinity for SNEDDS formulation was higher $(160.1 \pm 1.04 \mathrm{ng}$. $\mathrm{h} / \mathrm{ml})$ than the pure drug suspension formulation $135.3 \pm 2.02 \mathrm{ng} . \mathrm{h} / \mathrm{ml}$. Statistically, $\mathrm{AUC}_{0-\mathrm{t}}$ of the SNEDDS formulation was significantly higher $(p<0.05)$ as compared to pure drug suspension formulation. Higher amount of drug concentration in blood indicated better systemic absorption of Candesartan from SNEDDS formulation as compared to the pure drug suspension formulation. The results from this study suggest the requirement for potential use of candesartan as selfnanoemulsifying drug delivery systems.
\end{abstract}

Keywords: Candesartan, Hypertension, SNEDDS, Caproyl 90, Captex, 500, Zeta Potential.

DOI: 10.25004/IJPSDR.2018.100501

Int. J. Pharm. Sci. Drug Res. 2018; 10(5): 351-361

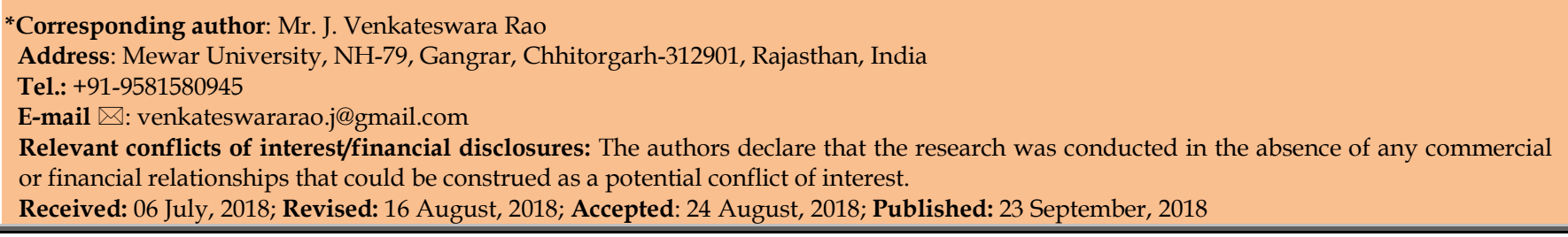

\section{INTRODUCTION}

Lipid based drug delivery has become one of the promising technology over the past decade due to the multiple roles of lipids in enhancing oral bioavailability. The success of these lipid based systems may also be attributed to the development of novel 
excipients with acceptable regulatory and safety profiles. [1] Depending upon the excipients and formulation techniques, a variety of systems such as physical mixture, liquid/ solid solutions, solid dispersions, self-micro and self-nanoemulsifying drug delivery systems (SMEDDS/ SNEDDS) may be developed. [2-3]

Candesartan cilexetil is a prodrug which has poor bioavailability because of poor solubility and belongs to BCS Class II. It is practically insoluble in water and has a partition coefficient of 9.8 at $\mathrm{pH} 7.4$ (According to the BCS classification developed by Amidon in conjugation with FDA guidance). [4] Candesartan cilexetil is an antihypertensive drug used in the treatment of hypertension. Due to its low solubility, it is required to be administered in high doses for therapeutic effectiveness. [5] Candesartan has a low bioavailability of only $15 \%$ and is weakly acidic in nature. ${ }^{[6]}$ Lipids are known to promote the transport of drugs through lymphatic route. [7] The possible mechanisms for this are increased transcellular absorption by increasing membrane fluidity, enhancing the paracellular transport by opening the tight junction, inhibiting the P-glycoprotein and cytochrome P450 to increase the intracellular concentration and formation of lipoprotein or chylomicron by phospholipid. ${ }^{[8]}$ Hence, theoretically one can assume an increase in oral bioavailability of Candesartan cilexetil.

In the present study SNEDDS of candesartan cilexetil were formulated and evaluated for in vitro drug release, FTIR, zeta potential, Scanning electron microscopy and particle size.

\section{MATERIALS AND METHODS}

Candesartan cilexetil was obtained as a gift sample from Aurobindo Pharma Limited, Hyderabad. Caproyl 90, Labrafil 1944 Cs and Labrafil 2125 were procured from Gattefose France. Sesame oil was obtained from Dr Reddy's Laboratories, India. Peceol and Castor oil were obtained from Croda Chemicals. Capmul MCM C8 was obtained from Strides Arcolab, Bangalore, India. Brij 35 was procured from Ind Chem International c/o Abitec Corporation, USA. Glycerol and Captex 500 were obtained from Loba Chemie Pvt Ltd, Mumbai. Propylene Glycol was obtained from Suvidinath Laboratories, Baroda, India. Cremophor EL was obtained from Signet Chemicals Corporation Pvt. Ltd. Mumbai. Tween 80 was obtained from Sigma Aldrich, USA. Transcutol $P$ and Labrasol were procured from Gattefosse India. PEG 400 was obtained from Otto Chemie Pvt. Ltd. Mumbai. India. Lauroglycol 90 was obtained from Ranbaxy Laboratories India. Captex 200 and Ethanol were procured from Abitec Ltd. Janesville.

\section{Methods}

\section{Solubility studies}

The solubility study was used to find out the suitable oil, surfactant and co-surfactant that possess good solubilizing capacity for Candesartan. An excess amount $(2 \mathrm{mg}$ ) of Candesartan was added into $2 \mathrm{ml}$ of each excipients (Oils -Capmul MCM C8, Castor oil, Capryol 90, Peceol, and Sesame oil,). Surfactants (Captex 500, Cremophor EL, Propylene glycol, Glycerol, Brij 35, Labrafil 2125 and Labrafil 1944Cs). Co-surfactants (Ethanol, Labrasol, Captex 200, Transcutol P, Tween 80, Lauroglycol 90 and PEG 400) and kept in mechanical shaker for 24 hours and centrifuged at 10,000 rpm for $20 \mathrm{~min}$ using a centrifuge. Supernatant was filtered through membrane filter using $0.45 \mu \mathrm{m}$ filter disk. Filtered solution was appropriately diluted with methanol, and UV absorbance was measured at $257 \mathrm{~nm}$. Concentration of dissolved drug was determined spectrophotometrically. [9]

\section{Pseudo ternary phase diagram}

To determine the concentration of components for the existing range of SNEDDS, pseudo ternary phase diagram was constructed using water titration method at ambient temperature $\left(25^{\circ} \mathrm{C}\right)$. Surfactant and cosurfactant (Smix) in each group were mixed in different volume ratio (1:1, 2:1, 3:1). Oil and surfactant/cosurfactant mixture (Smix) were mixed thoroughly in different volume ratios 1:9 to 9:1 (1:9, 2:8, 3:7, 4:6, 5:5, $6: 4,7: 3,8: 2$ and 9:1) $w / w$ for all the three Smix ratios 1:1,2:1, 3:1. The mixture of oil, surfactant and cosurfactant at certain ratios were titrated with water by drop wise addition under gentle agitation. Pseudo ternary plots were constructed using Chemix software. Deionized water was used as diluting medium and added into the formulation. The proper ratio of one excipient to another in the SNEDDS formulation was analyzed. [10]

\section{Visual observation}

A predetermined volume of mixture $(0.2 \mathrm{ml})$ was added to $300 \mathrm{ml}$ of water in a glass beaker under stirring and temperature was maintained at $37^{\circ} \mathrm{C}$ using a magnetic stirrer. The tendency of formation of emulsion was observed. If the droplet spreads easily in water, it was judged as 'good' and judged as 'bad' when there was milky or no emulsion or presence of oil droplets. By performing this test one can assess the self-emulsification property of the final formulation. [11] Development of SNEDDS formulation

Based on solubility studies, pseudo ternary phase diagram and visual observation, various formulations of Candesartan SNEDDS were prepared. Here, Capryol 90 was used as oil phase, Captex 500and Labrasol were used as surfactant and co-surfactant respectively. The composition was shown in Table 1. Candesartan was added in accurately weighed amount of oil into screwcapped glass vial and heated in a water bath at $40^{\circ} \mathrm{C}$. The surfactant and co-surfactant were added to the oily mixture using positive displacement pipette and stirred with magnetic bar. The formulation was further sonicated for $15 \mathrm{~min}$ and stored at room temperature.

Freeze Thawing (Thermodynamic Stability Studies) Formulations were subjected to freeze cycle $\left(-20^{\circ} \mathrm{C}\right.$ for 2 days followed by $40^{\circ} \mathrm{C}$ for 2 days). Only stable Int. J. Pharm. Sci. Drug Res. September-October, 2018, Vol 10, Issue 5 (351-361) 
formulations were selected for further studies. [12] The main objective of this study was to evaluate the phase separation and effect of temperature variations on SNEDDS formulations.

\begin{tabular}{|c|c|c|c|c|c|c|}
\hline $\begin{array}{c}\text { Smix } \\
\text { (Surfact } \\
\text { ant: } \\
\text { Co- } \\
\text { surfacta } \\
\text { nt) } \\
\end{array}$ & $\begin{array}{l}\text { Oil } \\
: \\
\text { Sm } \\
\text { ix }\end{array}$ & $\begin{array}{l}\text { Formula } \\
\text { tion } \\
\text { code }\end{array}$ & $\begin{array}{l}\text { Drug } \\
\text { Candesa } \\
\text { rtan) } \\
(\mathrm{mg})\end{array}$ & $\begin{array}{l}\text { Oil } \\
\text { (Capr } \\
\text { yol } \\
90) \\
(\mathrm{ml})\end{array}$ & $\begin{array}{c}\text { Surfact } \\
\text { ant } \\
\text { (Capte } \\
\times 500) \\
\text { (ml) }\end{array}$ & $\begin{array}{c}\text { Co- } \\
\text { surfact } \\
\text { ant } \\
\text { (Labra } \\
\text { sol) } \\
\text { (ml) } \\
\end{array}$ \\
\hline \multirow{6}{*}{ 1:1 } & $1: 9$ & F1 & 8 & 0.15 & 0.675 & 0.675 \\
\hline & $2: 8$ & $\mathrm{~F} 2$ & 8 & 0.3 & 0.6 & 0.6 \\
\hline & $3: 7$ & F3 & 8 & 0.45 & 0.525 & 0.525 \\
\hline & $4: 6$ & F4 & 8 & 0.6 & 0.45 & 0.45 \\
\hline & $5: 5$ & F5 & 8 & 0.75 & 0.375 & 0.375 \\
\hline & $6: 4$ & F6 & 8 & 0.9 & 0.3 & 0.3 \\
\hline \multirow{6}{*}{$2: 1$} & $4: 6$ & F7 & 8 & 0.6 & 0.6 & 0.3 \\
\hline & 5:5 & F8 & 8 & 0.75 & 0.5 & 0.25 \\
\hline & $6: 4$ & F9 & 8 & 0.9 & 0.4 & 0.2 \\
\hline & $7: 3$ & F10 & 8 & 1.05 & 0.3 & 0.15 \\
\hline & $8: 2$ & F11 & 8 & 1.2 & 0.2 & 0.1 \\
\hline & 9:1 & F12 & 8 & 1.35 & 0.1 & 0.05 \\
\hline \multirow{6}{*}{$3: 1$} & $2: 8$ & F13 & 8 & 0.3 & 0.9 & 0.3 \\
\hline & $3: 7$ & F14 & 8 & 0.45 & 0.787 & 0.262 \\
\hline & $4: 6$ & F15 & 8 & 0.6 & 0.675 & 0.225 \\
\hline & $5: 5$ & F16 & 8 & 0.75 & 0.5625 & 0.187 \\
\hline & $6: 4$ & F17 & 8 & 0.9 & 0.45 & 0.15 \\
\hline & $7: 3$ & F18 & 8 & 1.05 & 0.3375 & 0.1125 \\
\hline
\end{tabular}

\section{Centrifugation}

Centrifugation was performed at $3000 \mathrm{rpm}$ for 5 minutes and observed for phase separation. Stable formulations without any phase separation were selected for further studies. [13]

\section{$\%$ Transmittance measurement}

Various SNEDDS formulations were reconstituted with distilled water and the percent transmittance was measured at $243 \mathrm{~nm}$ using UV spectrophotometer against water as a blank. [14]

\section{Determination of drug content}

SNEDDS equivalent to $2 \mathrm{mg}$ of Candesartan were weighed accurately and dissolved in $100 \mathrm{ml}$ of $0.1 \mathrm{~N}$ $\mathrm{HCl}$ the solution was filtered, diluted suitable and drug content was analyzed at $\lambda_{\max } 257 \mathrm{~nm}$ against blank by UV spectrometer. The actual drug content was calculated using the following equation as follows:

$$
\begin{aligned}
& \text { Actual amount of drug in SNEDDS } \\
& \text { \% Drug content = - }
\end{aligned}
$$

\section{In-vitro dissolution studies}

The release of drug from liquid SNEDDS formulations and pure drug was determined using a US Pharmacopoeia Type II dissolution apparatus. SNEDDS of Candesartan equivalent to $8 \mathrm{mg}$ was filled in size " 0 " hard gelatin capsules. The dissolution media $0.1 \mathrm{~N} \mathrm{HCl}$ and temperature of the dissolution medium was maintained at $37^{\circ} \mathrm{C}$ operated at $50 \mathrm{rpm}$. An aliquot of 5 $\mathrm{ml}$ was withdrawn at predetermined intervals $2,5,10$, $15,20,25,30,45$, and 60 mins and filtered through $0.45 \mu \mathrm{m}$ pore size membrane filters. The removed volume was replaced each time with $5 \mathrm{ml}$ of fresh medium. The concentrations were assayed spectrophotometrically at $257 \mathrm{~nm}$.

\section{Characterization of SNEDDS}

\section{FTIR studies}

Analysis of Candesartan pure drug and physical mixtures of the drug with the excipients were carried out using diffuse reflectance spectroscopy (DRS)-FTIR with $\mathrm{KBr}$ disc. All the samples were dried under vacuum prior to obtaining any spectra in order to remove the influence of residual moisture. For each the spectrum, 8 scans were obtained at a resolution of $4 \mathrm{~cm}^{-1}$ from a frequency range of $400-4000 \mathrm{~cm}^{-1}$. An FTIR-8400S Spectrophotometer (Shimadzu, Japan) equipped with attenuated total reflectance (ATR) accessory was used to obtain the infrared spectra of drug in the isotropic mixtures of excipients.

\section{Determination of droplet size}

Photon correlation spectroscopy technique was used to determine the average droplet size of the optimized formulation. (Malvern Instrument UK). It is used to measure sizes between 10 and $5000 \mathrm{~nm}$. The selected formulations were diluted with deionized water and placed in an electrophoretic cell for measurement. [15]

\section{Determination of Zeta Potential}

The emulsion stability is directly related to the magnitude of the surface charge. In conventional SNEDDS, the charge on an oil droplet is negative because of the presence of free fatty acids. The zeta potential of the diluted SNEDDS formulation was measured using a zeta meter system. The SNEDDS were diluted with a ratio 1:2500 (v/v) with distilled water and mixed with magnetic stirrer. Zeta-potential of the resulting micro emulsion was determined using a Zetasizer. [16]

\section{Scanning Electron Microscopy}

Scanning electron microscopy (SEM) was applied to assess the shape and surface morphology of microspheres. The SNEDDS after converting to emulsion were mounted on metal stubs and the stub was then coated with conductive gold with sputter coater attached to the instrument (HITACHI, S-3700N). [17]

\section{Percent entrapment efficiency}

The contents of free drug were separated from nanoemulsion by ultrafiltration at 3500 Da with centrifugation at $3000 \mathrm{~g}$ for 5 to 10 minutes, followed by qualification using HPLC method. [18] The Entrapment Efficiency was calculated as follows.

$$
\text { Entrapment Efficiency }=\frac{\text { Total amount of drug in SNEDDS }}{\text { Total weight of ingredients in nanoemulsion }}
$$

\section{Stability studies}

Various in vitro parameters like \% yield, entrapment efficiency and in vitro release studies were evaluated during stability testing. It was carried out at $40^{\circ} \mathrm{C} \pm$ $2{ }^{\circ} \mathrm{C} / 75 \% \mathrm{RH} \pm 5 \% \mathrm{RH}$ for 6 months using stability chamber (Thermo Lab, Mumbai). Samples were withdrawn at predetermined intervals $0,30,90$ and 180 days period according to ICH guidelines. [19] 


\section{Pharmacokinetic study}

Animals

Healthy Wistar rats were (Weighing 150-180 g) selected for this study, all the animals were healthy during the period of the experiment. All efforts were made to maintain the animals under controlled environmental conditions (Temperature $25^{\circ} \mathrm{C}$, Relative Humidity $45 \%$ and $12 \mathrm{~h}$ alternate light and dark cycle) with $100 \%$ fresh air exchange in animal rooms, uninterrupted power and water supply. Rats were fed with standard diet and water ad libitum. [20-21] The protocol of animal study was approved by the institutional animal ethics committee (IAEC NO: IAEC/1657/CMRCP/T2/Ph D-16/70).

\section{Study Design}

Rats were divided in to two groups at random and each group contains 6 rats. The rats were fasted for 24 hours prior to the experiments. After 4 hours of dosing, foods were reoffered. First group was administered with pure Candesartan (as such) made suspension with 0.5\% methocel and second group was administered Prepared Candesartan SNEDDS diluted in $0.5 \%$ methanol by oral route at a dose of $10 \mathrm{mg} / \mathrm{kg}$. Then, $500 \mu \mathrm{L}$ blood samples were collected from the femoral artery at certain times $0,0.50,1,1.50,2,2.50,3,4,5,6,8,12,16$, 20, 24 h post dose and transferred into Eppendorf tubes containing heparin in order to prevent blood clotting. Plasma was separated by centrifugation of the blood at $5000 \mathrm{rpm}$ in cooling centrifuge for $5 \mathrm{~min}$ to 10 minutes and stored frozen at $-20^{\circ} \mathrm{C}$ until analysis. [22]

Determination of Candesartan in Rat plasma by HPLC method

Determination of Candesartan cilexetil and internal standard hydrochlorothiazide was carried out by using the chromatographic separation was achieved on Hibar C18 stationary phase $(150 \mathrm{~mm} \times 4.6 \mathrm{~mm}$ i.d; $5 \mu)$ with mobile phase containing phosphate buffer- acetonitrile (55:45) adjusted to $\mathrm{pH} 4.6$ using ortho phosphoric acid was used and injection volume of $20 \mu \mathrm{L}$, with a flow rate of $1.0 \mathrm{ml} / \mathrm{min}$. and effluents were monitored at 244 $\mathrm{nm}$. The retention times of Candesartan cilexetil and hydrochlorothiazide were $2.6 \mathrm{~min}$ and $3.6 \mathrm{~min}$, respectively. [23]

Pharmacokinetic analysis

The pharmacokinetic parameters employed to evaluate were maximum plasma concentration $\left(C_{\max }\right)$, time to attain $C_{\max }$ i.e., $\mathrm{T}_{\max }$ and $\mathrm{t}_{1 / 2}$ values, area under plasma concentration-time curve from zero to the last sampling time $\left(A U C_{0-t}\right)$, area under plasma concentration-time curve from zero to infinity $\left(A U C_{0}\right.$ $\infty)$. $A U C_{0-t}$ was calculated by the linear trapezoidal rule and $A U C_{0-\infty}$ from the following formula

$$
\mathrm{AUC}_{0-\infty}=\mathrm{AUC}_{0-\mathrm{t}}+\mathrm{C}_{\mathrm{t}} / \mathrm{K}_{\mathrm{E}}
$$

Win Nonlin $3.3^{\circledR}$ pharmacokinetic software (Pharsight Mountain View, CA USA) was used to perform the pharmacokinetic parameters. All values are expressed as the mean \pm SD. Statistical analysis was performed with Graph Pad InStat software (version 3.00, Graph Pad Software, San Diego, CA, USA) using one-way analysis of variance (ANOVA) followed by Tukey-
Kramer multiple comparison test. Difference with $p<0.05$ was statistically significant.

\section{RESULTS AND DISCUSSIONS \\ Solubility studies}

In the case of SNEDDS initially preliminary solubility analysis was carried out to select the appropriate excipient from various (Oils - Capmul MCM C8, Castor oil, Capryol 90, Peceol, and Sesame oil,). Surfactants (Captex 500, Cremophor EL, Propylene glycol, Glycerol, Brij 35, Labrafil 2125 and Labrafil 1944Cs); Co-surfactants (Ethanol, Labrasol, Captex 200, Transcutol P, Tween 80, Lauroglycol 90 and PEG 400). The solubility of pure drug was found to be 0.014 $\mathrm{mg} / \mathrm{ml}$ in water. Based on drug solubility, Capryol 90, Captex 500, Labrasol, were selected as oil, surfactant and co-surfactant respectively. The drug solubility values of these polymers were found to be highest when compared with the pure drug and other polymers (Tables 2, 3, 4 and Figures 1, 2, 3).

\begin{tabular}{cc} 
Table 2: Solubility studies of Candesartan in various oils \\
\hline Oils & Solubility (mg/ml) \\
\hline Capmul MCM C8 & $55.26 \pm 1.05$ \\
Capryol 90 & $80.25 \pm 3.28$ \\
Castor oil & $69.12 \pm 3.01$ \\
Peceol & $45.29 \pm 0.99$ \\
Sesame oil & $60.93 \pm 2.73$ \\
\hline
\end{tabular}

\begin{tabular}{cc} 
Table 3: Solubility studies of Candesartan in various surfactants \\
\hline Surfactants & Solubility $(\mathbf{m g} / \mathbf{m l})$ \\
\hline Glycerol & $180.23 \pm 2.56$ \\
Brij 35 & $105.1 \pm 1.01$ \\
Labrafil 2125 & $120.88 \pm 1.56$ \\
Labrafil 1944Cs & $148.20 \pm 1.99$ \\
Propylene glycol & $98.26 \pm 0.98$ \\
Captex 500 & $190.5 \pm 2.78$ \\
Cremophor EL & $152.9 \pm 2.01$ \\
\hline
\end{tabular}

\begin{tabular}{cc} 
Table 4: Solubility studies of Candesartan in various co-surfactants \\
\hline Co-surfactants & Solubility $(\mathbf{m g} / \mathbf{m l})$ \\
\hline Ethanol & $109.6 \pm 1.99$ \\
Labrasol & $156.5 \pm 3.53$ \\
Captex 200 & $130.2 \pm 2.89$ \\
Transcutol P & $95.60 \pm 1.58$ \\
Tween 80 & $120.1 \pm 2.05$ \\
Lauroglycol 90 & $89.91 \pm 0.85$ \\
PEG 400 & $140.25 \pm 3.01$ \\
\hline
\end{tabular}

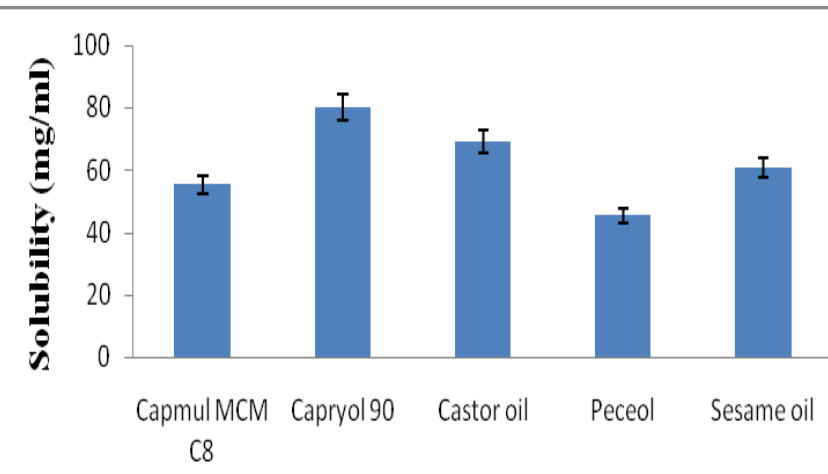

Oils

Fig. 1: Solubility studies of Candesartan in oils 


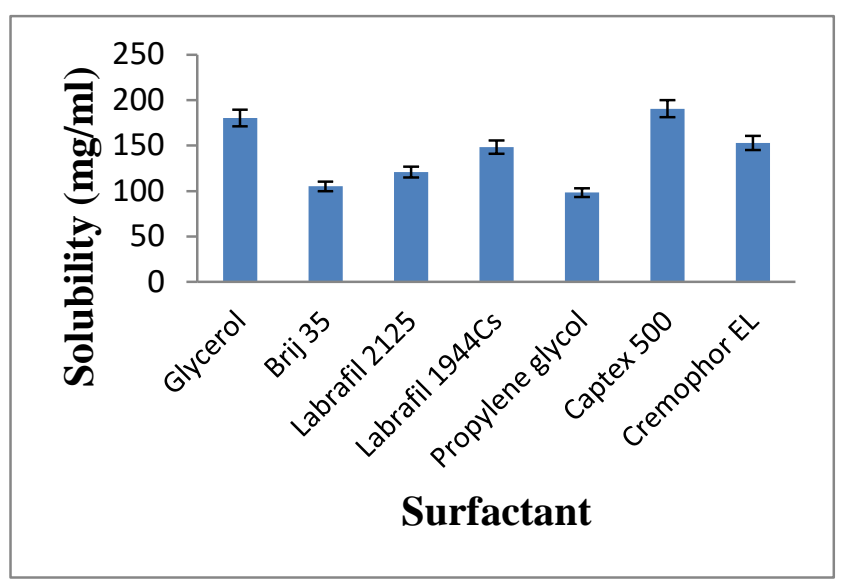

Fig. 2: Solubility studies of Candesartan in surfactant

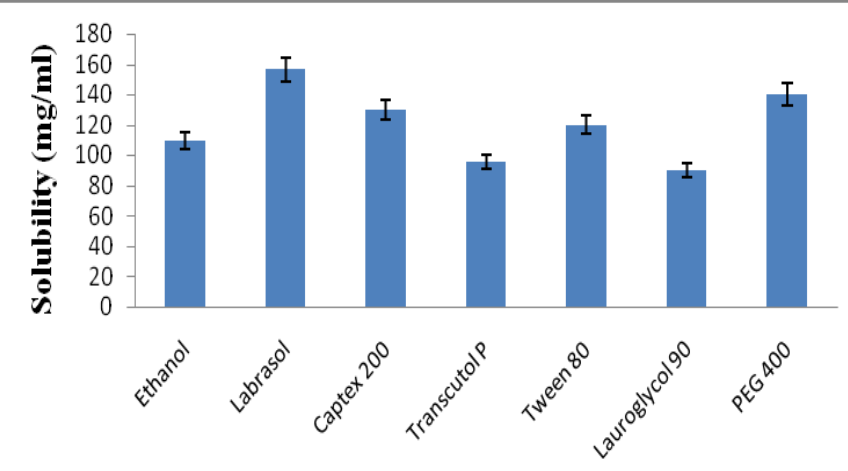

Co- surfactant

Fig. 3: Solubility studies of Candesartan in co-surfactants

Pseudo ternary phase diagram

From the solubility studies, Capryol 90, Captex 500 and Labrasol were selected as oil, surfactant and cosurfactant respectively. From the phase diagram indicated as Figure 4, it was observed that self emulsifying region was enhanced with increasing concentrations of surfactant and co-surfactant with oil. Efficiency of self-emulsification was good when the surfactant concentration increased (Figure 4).

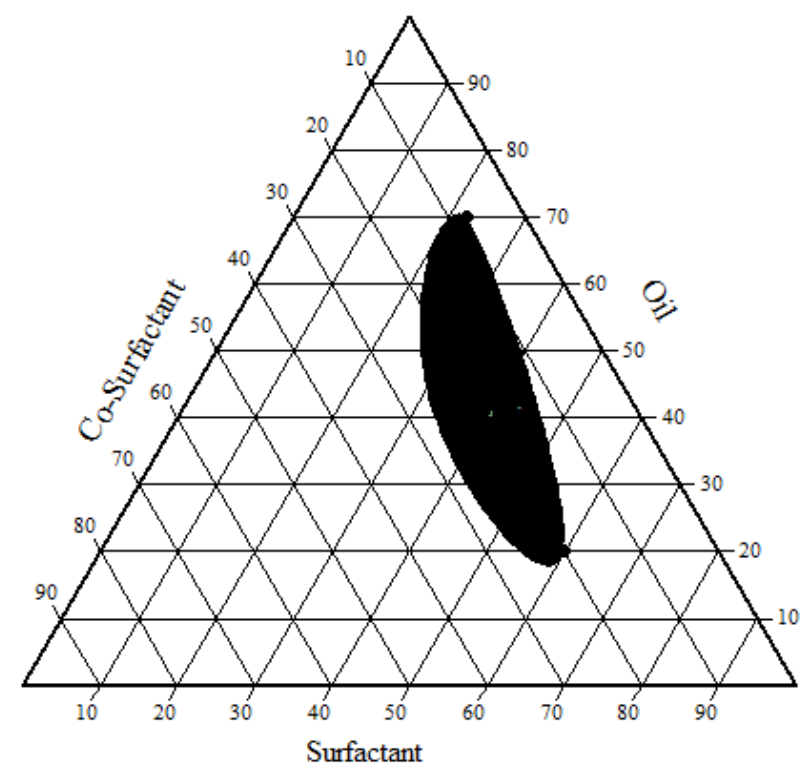

Fig. 4: Ternary phase diagram of Capryol 90, Captex 500 and Labrasol

\section{Visual observation}

With the use of visual observation method, the tendency of formation of emulsion was observed. Visual observation test was performed for different ratios by keeping the surfactant and co-surfactant ratio (Smix) as 1:1, 2:1 and 3:1. Grades were given to the ratios based on the tendency of formation of microemulsion. Ratios 2:8, 3:7, 5:5 and 6:4 of Smix 1:1 and 1:9, 4:6, 5:5, 8:2, 9:1 of Smix 2:1 and 2:8, 3:7, 4:6, 5:5 of Smix 3:1 showed rapid formation of micro emulsion within a minute having a clear appearance. Therefore, these ratios were selected for the formulation of SNEDDS (Tables 5, $6 \& 7$ and Figures 5, 6).

Table 5: Visual observation test for Smix (Surfactant: Co-surfactant) ratio 1:1

\begin{tabular}{ccc}
\hline Oil:Smix & Time of self emulsification $(\mathbf{m i n})$ & Grade \\
\hline $1: 9$ & $<2$ & III \\
$2: 8$ & $<1$ & I \\
$3: 7$ & $<1$ & I \\
$4: 6$ & $<1$ & I \\
$5: 5$ & $<1$ & I \\
$6: 4$ & $<1$ & I \\
$7: 3$ & $<1$ & I/II \\
$8: 2$ & $<2$ & III \\
$9: 1$ & $<2$ & III \\
\hline
\end{tabular}

Table 6: Visual observation test for Smix (surfactant: co-surfactant) ratio 2:1

\begin{tabular}{|c|c|c|}
\hline Oil:Smix & Time of self emulsification (min) & Grade \\
\hline $1: 9$ & $<1$ & I/II \\
\hline $2: 8$ & $<1$ & I/II \\
\hline $3: 7$ & $<2$ & III \\
\hline $4: 6$ & $<1$ & I \\
\hline $5: 5$ & $<1$ & I \\
\hline $6: 4$ & $<2$ & III \\
\hline $7: 3$ & $<2$ & III \\
\hline $8: 2$ & $<1$ & I \\
\hline $9: 1$ & $<1$ & I \\
\hline
\end{tabular}

Table 7: Visual observation test for Smix (surfactant: co-surfactant) ratio 3:1

\begin{tabular}{ccc}
\hline Oil:Smix & Time of self emulsification $(\mathbf{m i n})$ & Grade \\
\hline $\mathbf{1 : 9}$ & $<1$ & $\mathrm{I} / \mathrm{II}$ \\
$\mathbf{2 : 8}$ & $<1$ & $\mathrm{I}$ \\
$\mathbf{3 : 7}$ & $<1$ & $\mathrm{I}$ \\
$\mathbf{4 : 6}$ & $<1$ & $\mathrm{I}$ \\
$\mathbf{5 : 5}$ & $<1$ & $\mathrm{I}$ \\
$\mathbf{6 : 4}$ & $<2$ & $\mathrm{III}$ \\
$\mathbf{7 : 3}$ & $<1$ & $\mathrm{I} / \mathrm{II}$ \\
$\mathbf{8 : 2}$ & $<1$ & $\mathrm{I} / \mathrm{II}$ \\
$\mathbf{9 : 1}$ & $<2$ & $\mathrm{III}$ \\
\hline
\end{tabular}

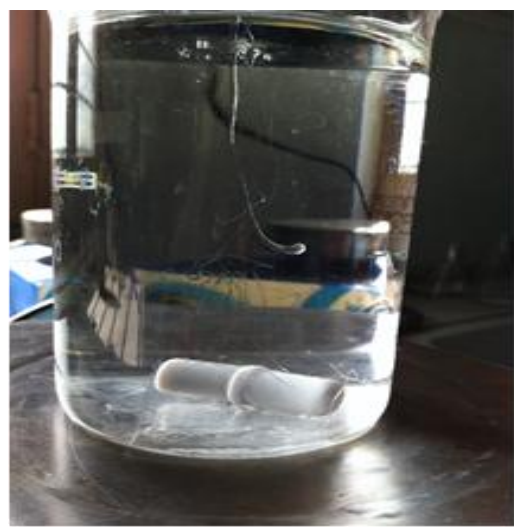

Fig. 5: Visual observation test 


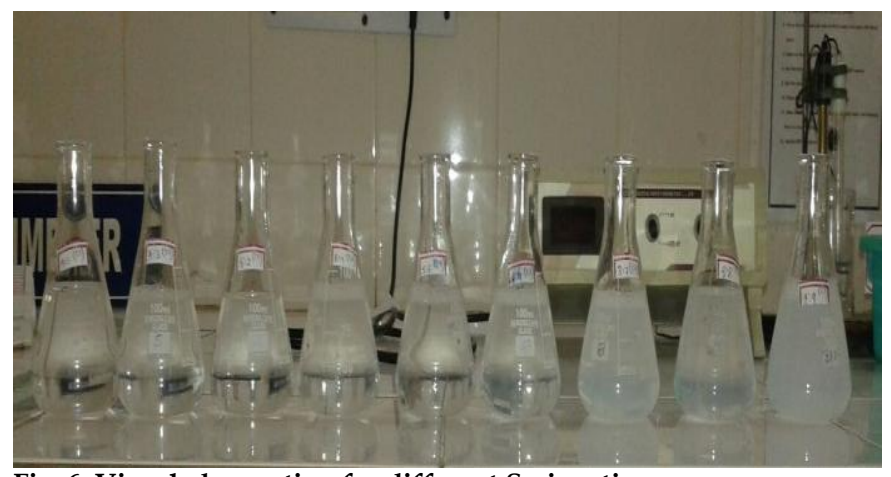

Fig. 6: Visual observation for different Smix ratios

\section{Preparation of Candesartan SNEDDS}

SNEDDS of Candesartan were prepared by using Capryol 90 (oil) Captex 500 (surfactant) and Labrasol (co-surfactant). In the present study, fifteen formulations were prepared (Table 8). All the formulations prepared were found to be clear and transparent. Pictorial representations of formulations F1 to F18 were shown in Figure 7.

Thermodynamic stability studies

In thermodynamic stability study, no phase separation and effect of temperature variations on prepared formulations were observed. There was no change in the visual description of samples after centrifugation freeze-thaw cycles. Formulations which are thermodynamically stable only those were selected for further characterization (Table 8).

Table 8: Thermodynamic stability studies of the formulations

\begin{tabular}{|c|c|c|c|}
\hline \multirow[b]{2}{*}{$\begin{array}{l}\text { Formulation } \\
\text { code }\end{array}$} & \multirow[b]{2}{*}{ Centrifugation } & \multicolumn{2}{|c|}{ Freeze thaw method } \\
\hline & & $\begin{array}{c}-20^{\circ} \mathrm{C} \text { for } 2 \\
\text { days }\end{array}$ & $\begin{array}{c}+40^{\circ} \mathrm{C} \text { for } 2 \\
\text { days }\end{array}$ \\
\hline F1 & No phase separation & No change & No change \\
\hline F2 & No phase separation & No change & No change \\
\hline F3 & No phase separation & No change & No change \\
\hline F4 & No phase separation & No change & No change \\
\hline F5 & No phase separation & No change & No change \\
\hline F6 & No phase separation & No change & No change \\
\hline F7 & No phase separation & No change & No change \\
\hline F8 & No phase separation & No change & No change \\
\hline F9 & No phase separation & No change & No change \\
\hline F10 & No phase separation & No change & No change \\
\hline F11 & No phase separation & No change & No change \\
\hline F12 & No phase separation & No change & No change \\
\hline F13 & No phase separation & No change & No change \\
\hline F14 & No phase separation & No change & No change \\
\hline F15 & No phase separation & No change & No change \\
\hline F16 & No phase separation & No change & No change \\
\hline F17 & No phase separation & No change & No change \\
\hline F18 & No phase separation & No change & No change \\
\hline
\end{tabular}

\section{Transmittance measurement}

The visual observation of all the formulations was shown in Table 9. The clarity of nanoemulsions was checked by transparency, measured in terms of transmittance $(\% \mathrm{~T})$. SNEDDS forms $\mathrm{o} / \mathrm{w}$ microemulsion since water is external phase Formulation $\mathrm{F} 17$ has \% transmittance value greater than $98 \%$. These results indicate the high clarity of microemulsion. In case of other systems $\% \mathrm{~T}$ values were less than 99\% suggesting less clarity of microemulsions. This may be due to greater particle size of the formulation. Due to higher particle size, oil globules may reduce the transparency of microemulsion and thereby values of $\% \mathrm{~T}$ are affected (Table 9).

Table 9: Visual observation and \% Transmittance of different formulations

\begin{tabular}{cccc}
\hline S. No. & $\begin{array}{c}\text { Formulation } \\
\text { Code }\end{array}$ & Visual observation & \% Transmittance \\
\hline 1 & F1 & Turbid & 75.27 \\
2 & F2 & Turbid & 88.72 \\
3 & F3 & Slightly clear & 90.27 \\
4 & F4 & Slightly clear & 92.88 \\
5 & F5 & Turbid & 66.22 \\
6 & F6 & Transparent & 86.77 \\
7 & F7 & Transparent & 93.57 \\
8 & F8 & Turbid & 86.37 \\
9 & F9 & Transparent & 95.34 \\
10 & F10 & Slightly clear & 88.52 \\
11 & F11 & Transparent & 94.28 \\
12 & F12 & Transparent & 97.31 \\
13 & F13 & Turbid & 88.79 \\
14 & F14 & Slightly clear & 91.27 \\
15 & F15 & Transparent & 95.37 \\
16 & F16 & Transparent & 94.37 \\
17 & F17 & Transparent & 98.37 \\
18 & F18 & Slightly clear & 90.11 \\
\hline
\end{tabular}

\section{Drug content of SNEDDS}

Actual drug content of all 18 formulations are shown in table 10. The drug content of the prepared SNEDDS was found to be in the range of $88.27-98.77 \%$. Maximum \% drug content i.e. $98.77 \%$ was found in the formulation F17.

\begin{tabular}{ccc}
$\begin{array}{c}\text { Table 10: } \% \\
\text { Candesartan SNEDDS }\end{array}$ & Drug Content & for \\
\multicolumn{2}{c}{ different } & formulations \\
\hline S. No. & Formulation code & \% Drug content \\
\hline 1 & F1 & 90.79 \\
2 & F2 & 93.27 \\
3 & F3 & 89.79 \\
4 & F4 & 93.67 \\
5 & F5 & 88.27 \\
6 & F6 & 95.77 \\
7 & F7 & 97.22 \\
8 & F8 & 92.77 \\
9 & F9 & 96.11 \\
10 & F10 & 90.88 \\
11 & F11 & 92.77 \\
12 & F12 & 91.92 \\
13 & F13 & 94.22 \\
14 & F14 & 94.04 \\
15 & F15 & 95.00 \\
16 & F16 & 90.27 \\
17 & F17 & 98.77 \\
18 & F18 & 95.27 \\
\hline
\end{tabular}

\section{In-vitro dissolution studies of SNEDDS}

The faster dissolution from SNEDDS may be attributed to the fact that in this formulation, the drug is a solubilized form and upon exposure to dissolution medium results in small droplet that can dissolve rapidly in the dissolution medium. The release from liquid SNEDDS formulation F17 was faster than other SNEDDS formulations and pure drug substance indicating influence of droplet size on the rate of drug dissolution (Tables 11, 12, 13 and Figures 7, 8, 9). 
J. Venkateswara Rao et al. / Self Nanoemulsifying Drug Delivery System of Candesartan Cilexetil with..........

Table 11: Dissolution profiles of various formulations (F 1 to F6)

\begin{tabular}{|c|c|c|c|c|c|c|c|}
\hline \multirow{2}{*}{$\begin{array}{l}\text { Time } \\
\text { (min) }\end{array}$} & \multicolumn{7}{|c|}{$\begin{array}{c}\text { Dissolution media - 0.1N HCl (\% drug release) } \\
\text { Formulation Code } \mathrm{F} 1 \text { to } \mathrm{F} 6(1: 1)\end{array}$} \\
\hline & Pure drug & F1 & F2 & F3 & F4 & F5 & F6 \\
\hline 0 & $0 \pm 0$ & $0 \pm 0$ & $0 \pm 0$ & $0 \pm 0$ & $0 \pm 0$ & $0 \pm 0$ & $0 \pm 0$ \\
\hline 2 & $4.98 \pm 0.02$ & $15.12 \pm 0.68$ & $14.98 \pm 0.66$ & $14.03 \pm 0.66$ & $11.26 \pm 0.52$ & $13.25 \pm 0.65$ & $12.99 \pm 0.62$ \\
\hline 5 & $7.28 \pm 0.09$ & $18.25 \pm 0.98$ & $19.46 \pm 0.99$ & $17.66 \pm 0.97$ & $18.01 \pm 0.98$ & $17.99 \pm 0.97$ & $16.25 \pm 0.96$ \\
\hline 10 & $11.25 \pm 0.52$ & $25.89 \pm 1.59$ & $22.13 \pm 1.25$ & $20.19 \pm 1.21$ & $22.16 \pm 1.25$ & $25.16 \pm 1.28$ & $28.16 \pm 1.39$ \\
\hline 15 & $14.68 \pm 0.61$ & $35.69 \pm 2.35$ & $39.15 \pm 2.55$ & $39.45 \pm 2.56$ & $33.25 \pm 2.35$ & $38.19 \pm 2.45$ & $35.19 \pm 2.35$ \\
\hline 20 & $22.13 \pm 1.25$ & $59.56 \pm 3.25$ & $49.16 \pm 2.98$ & $48.99 \pm 2.96$ & $49.45 \pm 2.98$ & $48.67 \pm 2.96$ & $49.99 \pm 2.98$ \\
\hline 25 & $29.27 \pm 1.89$ & $69.25 \pm 3.59$ & $65.16 \pm 3.25$ & $69.88 \pm 3.45$ & $55.12 \pm 3.25$ & $68.15 \pm 3.45$ & $65.25 \pm 3.25$ \\
\hline 30 & $33.09 \pm 2.20$ & $72.19 \pm 3.65$ & $79.89 \pm 3.98$ & $79.98 \pm 3.99$ & $63.12 \pm 3.35$ & $74.22 \pm 3.95$ & $79.45 \pm 3.99$ \\
\hline 45 & $39.98 \pm 2.56$ & $85.99 \pm 4.86$ & $86.16 \pm 4.56$ & $89.25 \pm 4.99$ & $75.16 \pm 3.98$ & $85.66 \pm 4.59$ & $86.22 \pm 4.60$ \\
\hline 60 & $46.98 \pm 2.98$ & $93.12 \pm 5.03$ & $90.78 \pm 5.01$ & $92.25 \pm 5.02$ & $89.99 \pm 4.99$ & $91.88 \pm 5.01$ & $90.35 \pm 5.00$ \\
\hline
\end{tabular}

Table 12: Dissolution profiles of various formulations (F 7 to F12)

\begin{tabular}{|c|c|c|c|c|c|c|c|}
\hline \multirow{2}{*}{$\begin{array}{l}\text { Time } \\
\text { (min) }\end{array}$} & \multicolumn{7}{|c|}{$\begin{array}{c}\text { Dissolution media - } 0.1 \mathrm{~N} \mathrm{HCl}(\% \text { drug release }) \\
\text { Formulation Code F7 to F12 (2:1) }\end{array}$} \\
\hline & Pure drug & F7 & F8 & F9 & F10 & F11 & F12 \\
\hline 0 & $0 \pm 0$ & $0 \pm 0$ & $0 \pm 0$ & $0 \pm 0$ & $0 \pm 0$ & $0 \pm 0$ & $0 \pm 0$ \\
\hline 2 & $4.98 \pm 0.02$ & $12.58 \pm 0.54$ & $8.78 \pm 0.09$ & $13.25 \pm 0.60$ & $11.85 \pm 0.52$ & $10.99 \pm 0.45$ & $9.98 \pm 0.15$ \\
\hline 5 & $7.28 \pm 0.09$ & $14.98 \pm 0.62$ & $15.67 \pm 0.68$ & $18.36 \pm 0.97$ & $20.19 \pm 0.99$ & $18.15 \pm 0.98$ & $15.16 \pm 0.68$ \\
\hline 10 & $11.25 \pm 0.52$ & $25.67 \pm 1.59$ & $22.15 \pm 1.25$ & $25.67 \pm 1.56$ & $22.98 \pm 1.28$ & $28.96 \pm 1.99$ & $28.18 \pm 1.99$ \\
\hline 15 & $14.68 \pm 0.61$ & $39.15 \pm 2.85$ & $38.25 \pm 2.84$ & $39.16 \pm 2.85$ & $35.16 \pm 2.45$ & $34.12 \pm 2.33$ & $36.22 \pm 2.46$ \\
\hline 20 & $22.13 \pm 1.25$ & $49.67 \pm 2.98$ & $50.12 \pm 3.22$ & $52.16 \pm 3.18$ & $42.98 \pm 2.96$ & $43.55 \pm 2.97$ & $44.25 \pm 2.98$ \\
\hline 25 & $29.27 \pm 1.89$ & $55.12 \pm 3.45$ & $59.99 \pm 3.45$ & $55.89 \pm 3.46$ & $49.55 \pm 2.98$ & $54.16 \pm 3.44$ & $58.16 \pm 3.33$ \\
\hline 30 & $33.09 \pm 2.20$ & $75.18 \pm 3.92$ & $65.36 \pm 3.55$ & $62.13 \pm 3.51$ & $52.18 \pm 3.45$ & $69.89 \pm 3.58$ & $69.28 \pm 3.59$ \\
\hline 45 & $39.98 \pm 2.56$ & $80.19 \pm 4.58$ & $78.99 \pm 3.95$ & $75.99 \pm 3.92$ & $69.55 \pm 3.58$ & $79.99 \pm 3.96$ & $75.19 \pm 3.92$ \\
\hline 60 & $46.98 \pm 2.98$ & $90.25 \pm 5.01$ & $85.19 \pm 4.86$ & $89.99 \pm 4.99$ & $80.1 \pm 4.58$ & $91.1 \pm 5.02$ & $92.19 \pm 5.03$ \\
\hline
\end{tabular}

Table 13: Dissolution profiles of various formulations (F 13 to F18)

\begin{tabular}{|c|c|c|c|c|c|c|c|}
\hline \multirow{2}{*}{$\begin{array}{l}\text { Time } \\
\text { (min) }\end{array}$} & \multicolumn{7}{|c|}{$\begin{array}{c}\text { Dissolution media - 0.1N HCl (\% drug release) } \\
\text { Formulation Code F13 to F18 (3:1) } \\
\end{array}$} \\
\hline & Pure drug & F13 & F14 & F15 & F16 & F17 & F18 \\
\hline 0 & $0 \pm 0$ & $0 \pm 0$ & $0 \pm 0$ & $0 \pm 0$ & $0 \pm 0$ & $0 \pm 0$ & $0 \pm 0$ \\
\hline 2 & $4.98 \pm 0.02$ & $10.12 \pm 0.45$ & $13.12 \pm 0.56$ & $12.11 \pm 0.54$ & $11.03 \pm 0.52$ & $17.98 \pm 0.81$ & $15.68 \pm 0.65$ \\
\hline 5 & $7.28 \pm 0.09$ & $15.67 \pm 0.68$ & $18.25 \pm 0.91$ & $19.20 \pm 0.92$ & $14.12 \pm 0.61$ & $25.23 \pm 1.89$ & $21.05 \pm 1.02$ \\
\hline 10 & $11.25 \pm 0.52$ & $29.12 \pm 1.98$ & $29.66 \pm 1.98$ & $23.52 \pm 1.55$ & $25.98 \pm 1.80$ & $38.65 \pm 2.51$ & $33.98 \pm 2.21$ \\
\hline 15 & $14.68 \pm 0.61$ & $35.98 \pm 2.25$ & $48.12 \pm 2.98$ & $39.16 \pm 2.56$ & $32.15 \pm 2.22$ & $55.67 \pm 3.45$ & $45.19 \pm 2.88$ \\
\hline 20 & $22.13 \pm 1.25$ & $49.17 \pm 2.88$ & $52.13 \pm 3.46$ & $58.12 \pm 3.49$ & $49.97 \pm 2.98$ & $69.03 \pm 3.88$ & $53.67 \pm 3.45$ \\
\hline 25 & $29.27 \pm 1.89$ & $59.25 \pm 3.56$ & $65.03 \pm 3.62$ & $70.25 \pm 3.99$ & $65.11 \pm 3.65$ & $78.25 \pm 4.01$ & $68.13 \pm 3.60$ \\
\hline 30 & $33.09 \pm 2.20$ & $65.12 \pm 3.79$ & $72.25 \pm 3.91$ & $72.19 \pm 3.91$ & $72.19 \pm 3.92$ & $80.11 \pm 4.45$ & $75.98 \pm 3.99$ \\
\hline 45 & $39.98 \pm 2.56$ & $78.55 \pm 4.02$ & $81.98 \pm 4.56$ & $80.15 \pm 4.25$ & $79.89 \pm 4.01$ & $88.97 \pm 4.72$ & $82.09 \pm 4.35$ \\
\hline 60 & $46.98 \pm 2.98$ & $89.28 \pm 4.75$ & $90.1 \pm 5.01$ & $91.25 \pm 5.02$ & $89.99 \pm 4.75$ & $99.12 \pm 5.10$ & $90.99 \pm 5.01$ \\
\hline
\end{tabular}

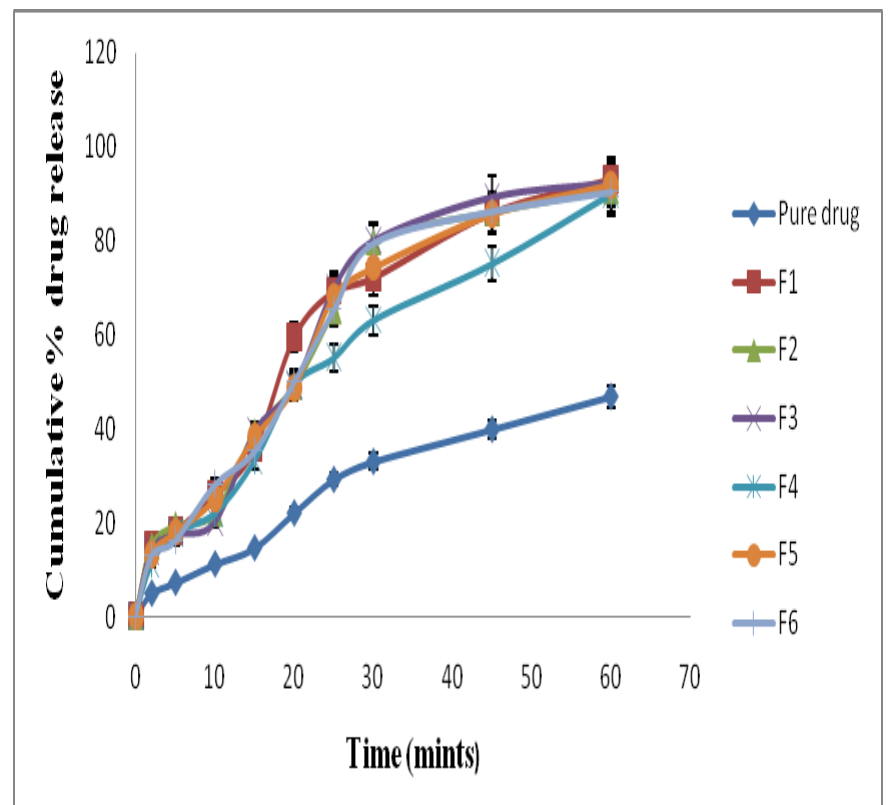

Fig. 7: Dissolution profiles of Candesartan pure drug and formulations (F1 to F6)

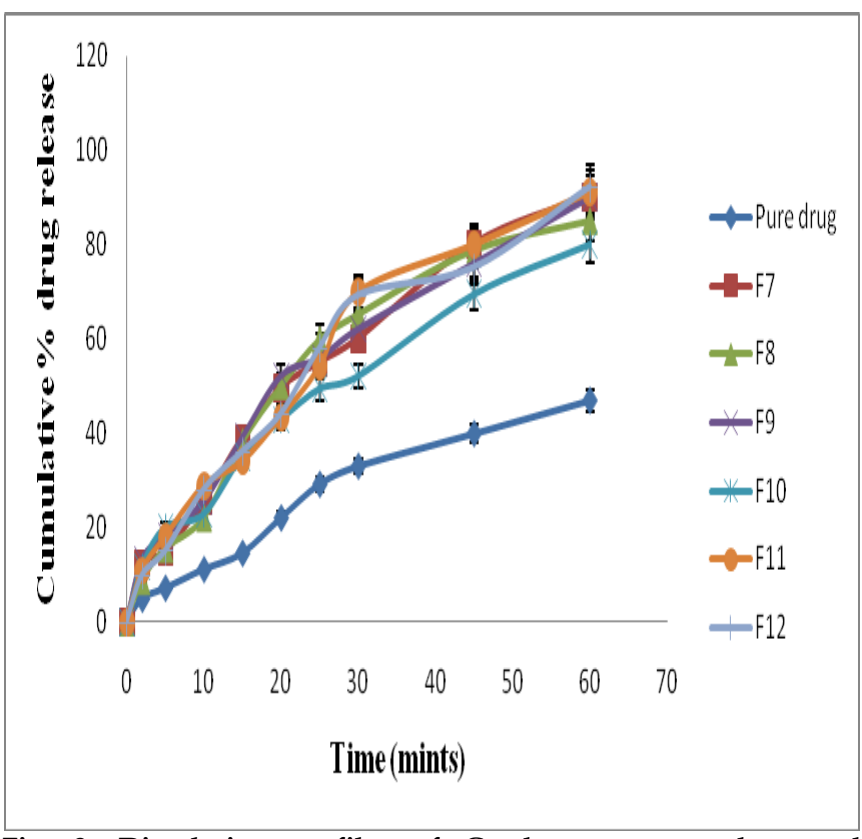

Fig. 8: Dissolution profiles of Candesartan pure drug and formulations (F7 to F12) 


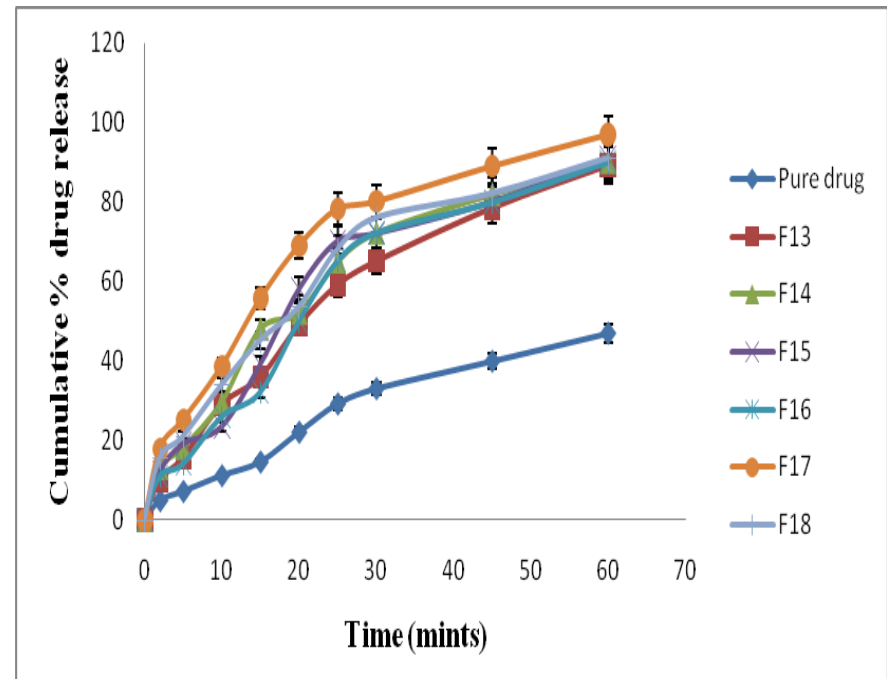

Fig. 9: Dissolution profiles of Candesartan pure drug and formulations (F13 to F18)

Interpretation of FTIR data
The FTIR spectra of optimized formulation were having similar fundamental peaks and pattern when compared with the pure drug (Figure 10). Thus there are no significant interactions among the drug and excipients. The optimized formulation of Candesartan spectrum was shown in Figure 11.

Particle size analysis of SNEDDS

Droplet size determines the rate and extent of drug release as well as drug absorption. Smaller the particle size, larger the interfacial surface area which may lead to more rapid absorption and improved bioavailability. SNEDDS with a mean droplet size below $200 \mathrm{~nm}$ exhibit excellent bioavailability. The particle size of the emulsion is a crucial factor in self-emulsification performance because it determines the rate and extent of drug release as well as absorption. The particle size of the optimized SNEDDS formulation (F17) was found to be $51.7 \mathrm{~nm}$ \& Z-Average of $59.2 \mathrm{~nm}$ indicating all the particles were in the nanometer range (Figure 12).

Ф SHIMADZU

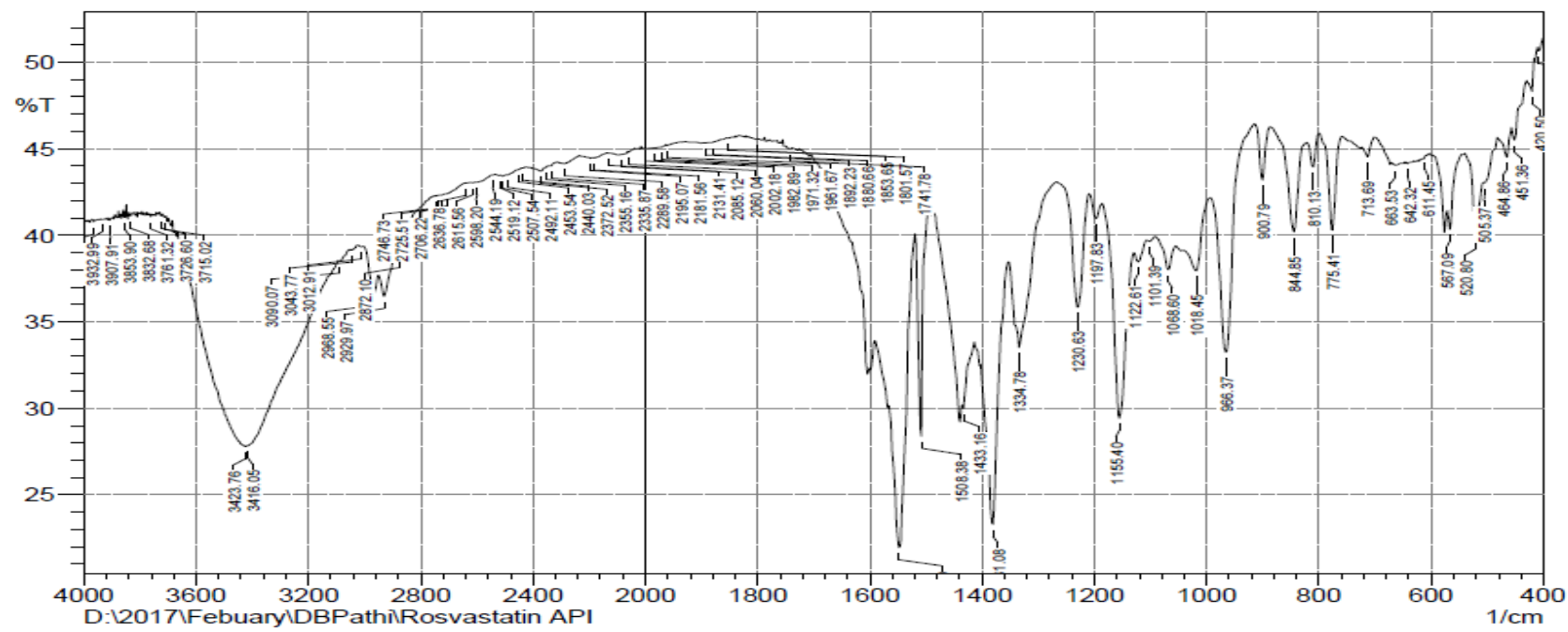

Fig. 10: FTIR Spectroscopy of Candesartan pure drug

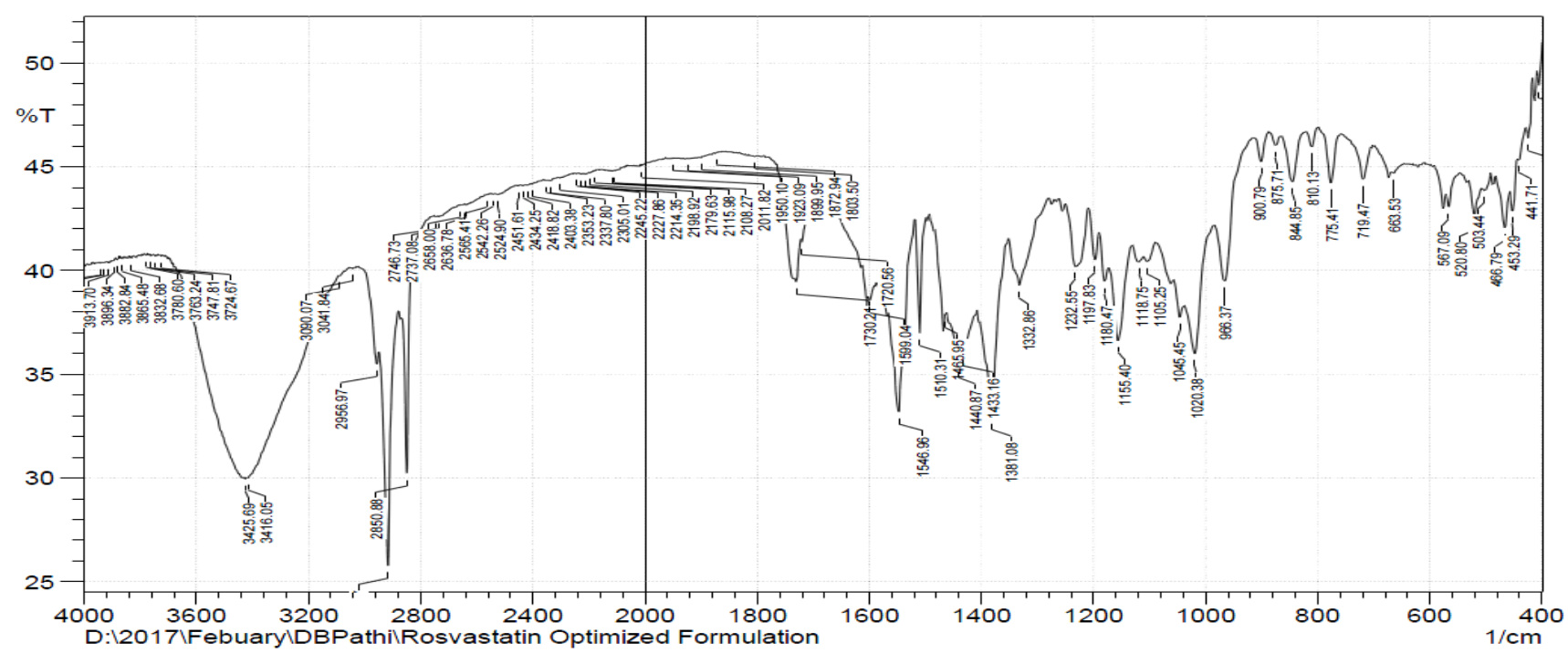

Fig. 11: FTIR Spectroscopy of Candesartan optimized formulation F17 

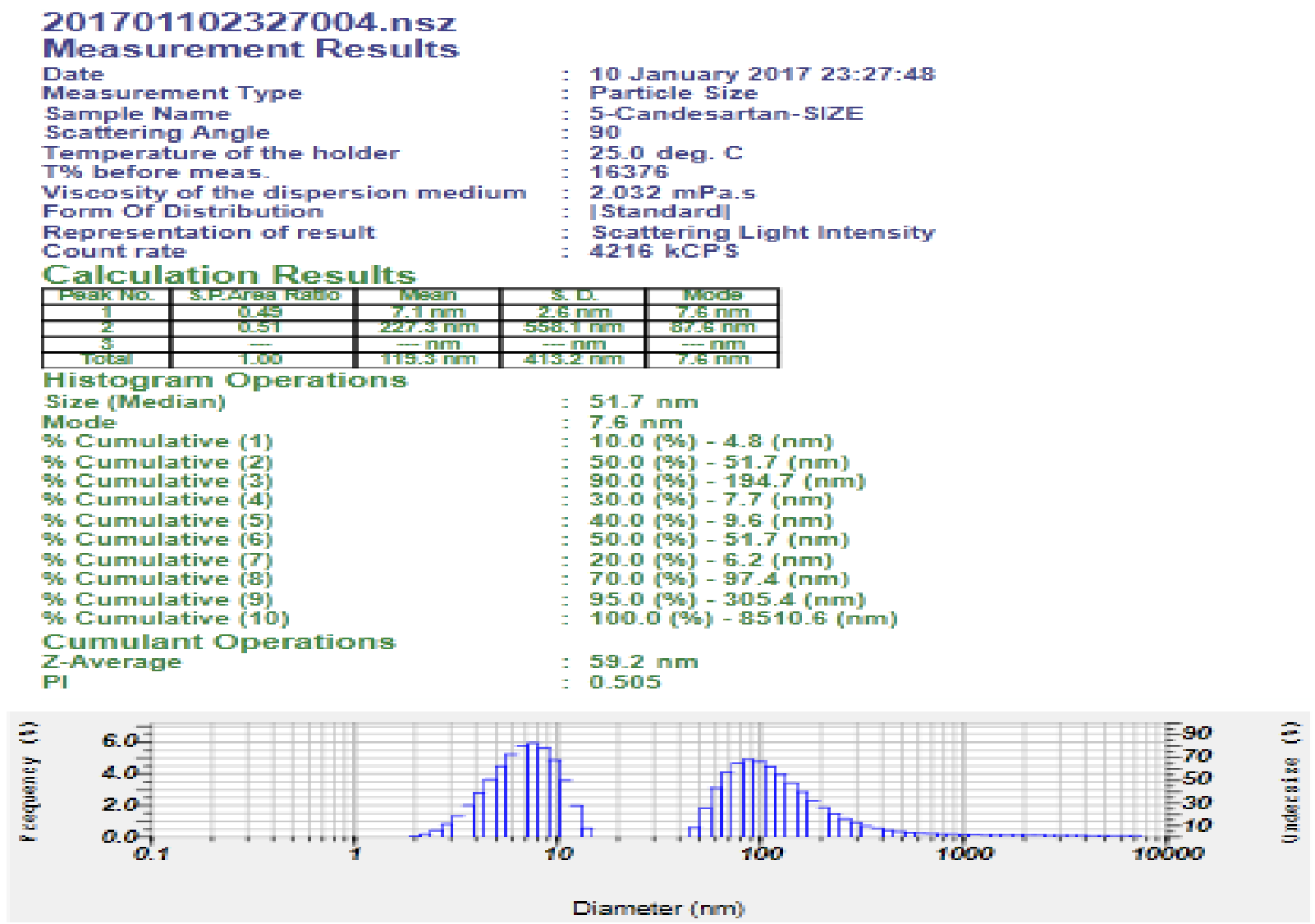

Fig. 12: Particle size analysis of optimized formulation F17

\section{HORIBA SZ100 Z}

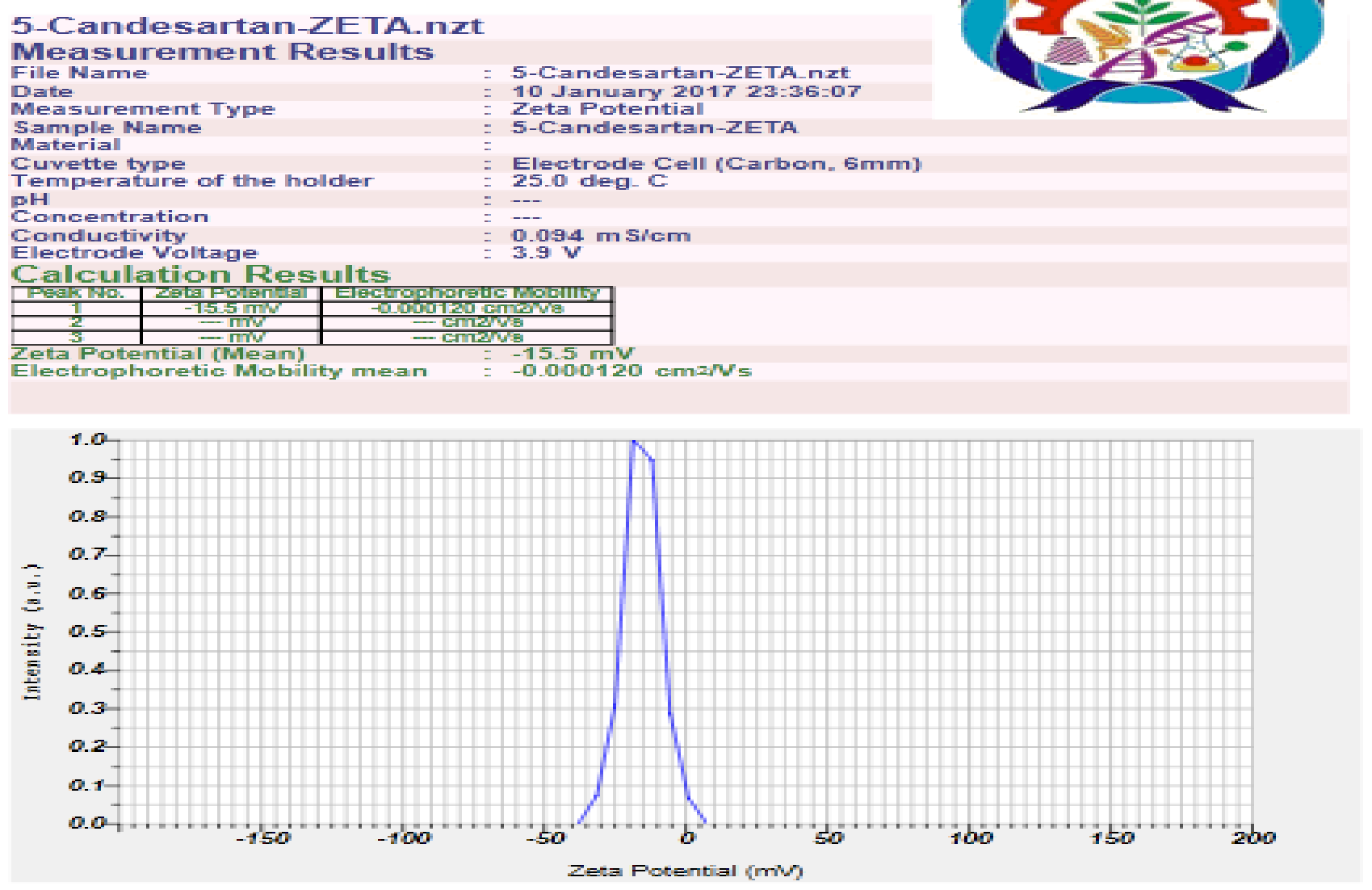

Fig. 13: Zeta potential of the optimized formulation F17 

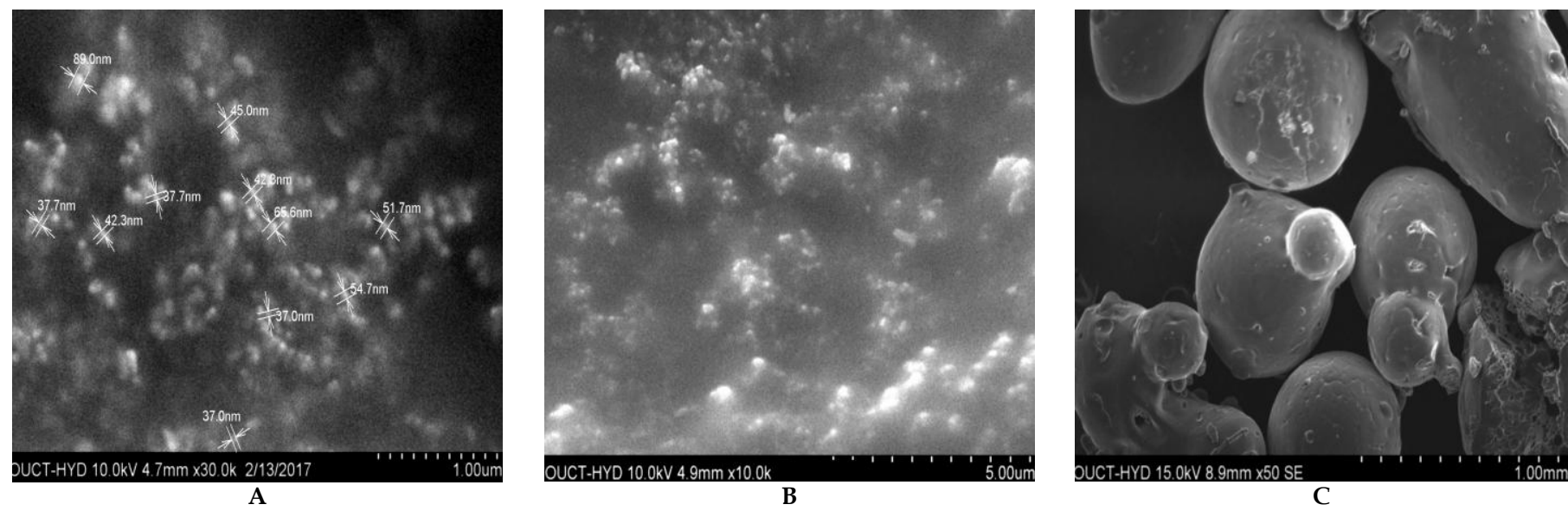

Fig. 14: Scanning electron microscopy of optimized Candesartan formulation F17

\section{Zeta potential of SNEDDS}

Zeta potential is responsible for the degree of repulsion between adjacent, similarly charged, dispersed droplets. A zeta potential value of $\pm 30 \mathrm{mV}$ is sufficient for the stability of a micro emulsion. The zeta potential of the optimized SNEDDS formulation (F17) was found to be $-15.5 \mathrm{mV}$ which comply with the requirement of the zeta potential for stability (Figure 13).

SEM studies

Scanning electron microscope studies of optimized formulation of Candesartan (F17) revealed oval shaped globules. The size is within nanometers. There are clear liquid droplets without any pores (Figure 14).

\section{Stability studies}

The Candesartan SNEDDS F17 formulation was filled in hard gelatin capsules as the final dosage form and subjected to stability studies for 6 months. There was no significant change in the drug content and drug release. It was also seen that the formulation were compatible with the hard gelatin capsule shells, as there was no sign of capsule shell deformation. There was no significant change in the appearance, or micro emulsifying property.

Pharmacokinetic parameters comparison for pure drug suspension and SNEDDS

Figure 15 shows the plasma concentration-time curve in Wistar rats after a single oral dose of Candesartan SNEDDS formulation as compared to Candesartan pure suspension. At all the indicated time points, the Candesartan plasma concentrations in rats treated with SNEDDS formulation was significantly higher than those treated with pure drug. Pharmacokinetic parameters of Candesartan after oral administration of the two formulations in Wistar rats are shown in Table 9. $\mathrm{C}_{\max }$ of the SNEDDS $35.2 \pm 0.02 \mathrm{ng} / \mathrm{ml}$ was significant $(p<0.05)$ as compared to the pure drug suspension formulation $25.1 \pm 0.03 \mathrm{ng} / \mathrm{ml}$. $\mathrm{T}_{\max }$ of both SNEDDS formulation and pure drug suspension was $1.00 \pm 0.03 \mathrm{~h}$ and $2.00 \pm 0.01 \mathrm{~h}$, respectively. AUC is an important parameter in evaluating bioavailability of drug from dosage form, as it represents the total integrated area under the blood concentration time profile and represents the total amount of drug reaching the systemic circulation after oral administration. $\quad \mathrm{AUC}_{0-\infty}$ infinity for SNEDDS formulation was higher $(160.1 \pm 1.04 \mathrm{ng} . \mathrm{h} / \mathrm{ml})$ than the pure drug suspension formulation $135.3 \pm 2.02$ ng.h $/ \mathrm{ml}$. Statistically, $\mathrm{AUC}_{0-\mathrm{t}}$ of the SNEDDS formulation was significantly higher $(p<0.05)$ as compared to pure drug suspension formulation. Higher amount of drug concentration in blood indicated better systemic absorption of Candesartan from SNEDDS formulation as compared to the pure drug suspension formulation.

Table 9: Pharmacokinetic Parameters of Candesartan SNEDDS formulation and pure drug

\begin{tabular}{ccc}
\hline $\begin{array}{c}\text { Pharmacokinetic } \\
\text { parameters }\end{array}$ & $\begin{array}{c}\text { Candesartan Pure } \\
\text { drug }\end{array}$ & $\begin{array}{c}\text { Candesartan - } \\
\text { SNEDDS Optimized } \\
\text { Formulation }\end{array}$ \\
\hline $\mathrm{C}_{\max }(\mathrm{ng} / \mathrm{ml})$ & $25.1 \pm 0.03$ & $35.2 \pm 0.02$ \\
$\mathrm{AUC}_{0-\mathrm{t}}(\mathrm{ng} . \mathrm{h} / \mathrm{ml})$ & $82.2 \pm 1.02$ & $104.4 \pm 1.01$ \\
$\mathrm{AUC}_{0-\text {-inf }}(\mathrm{ng} . \mathrm{h} / \mathrm{ml})$ & $135.3 \pm 2.02$ & $160.1 \pm 1.04$ \\
$\mathrm{~T}_{\max }(\mathrm{h})$ & $2.00 \pm 0.01$ & $1.00 \pm 0.03$ \\
$\mathrm{t}_{1 / 2}(\mathrm{~h})$ & $4.52 \pm 0.02$ & $3.02 \pm 0.02$ \\
\hline
\end{tabular}

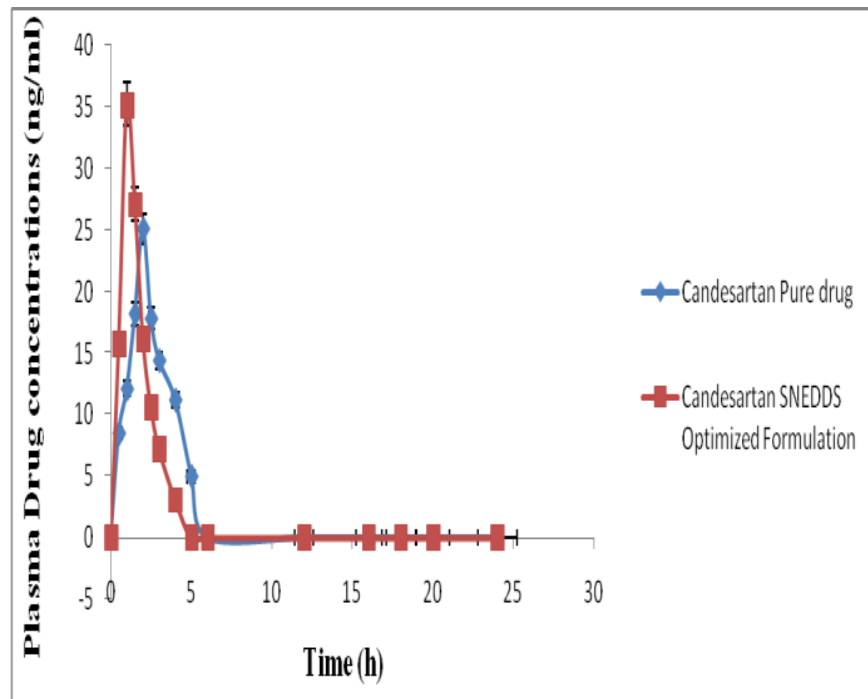

Fig. 15: Plasma concentration profiles of Candesartan SNEDDS and pure drug

In the present study, SNEDDS comprising of Capryol 90, Captex 500, Labrasol were prepared for enhancing the dissolution and bioavailability of candesartan. 
SNEDDS were optimized based on the optimum globule size, increased dissolution and drug release. Nearly complete drug release was achieved from the formulation F17 which is significantly higher as compared to a conventional dosage form. From in vivo bioavailability studies $C_{\max }$ of the SNEDDS $35.2 \pm 0.02$ $\mathrm{ng} / \mathrm{ml}$ was significant $(p<0.05)$ as compared to the pure drug suspension formulation $25.1 \pm 0.03 \mathrm{ng} / \mathrm{ml}$. $\mathrm{T}_{\max }$ of both SNEDDS formulation and pure drug suspension was $1.00 \pm 0.03 \mathrm{~h}$ and $2.00 \pm 0.01 \mathrm{~h}$, respectively. AUC is an important parameter in evaluating bioavailability of drug from dosage form, $\mathrm{AUC}_{0-\infty}$ infinity for SNEDDS formulation was higher $(160.1 \pm 1.04 \mathrm{ng} . \mathrm{h} / \mathrm{ml})$ than the pure drug suspension formulation $135.3 \pm 2.02$ ng.h/ml. Statistically, $\mathrm{AUC}_{0-\mathrm{t}}$ of the SNEDDS formulation was significantly higher $(p<0.05)$ as compared to pure drug suspension formulation. Higher amount of drug concentration in blood indicated better systemic absorption of Candesartan from SNEDDS formulation as compared to the pure drug suspension formulation. The results from this study suggest the requirement for potential use of Candesartan as selfnanoemulsifying drug delivery systems. Thus the developed SNEDDS can be used as an effective approach for the management of hypertension with low drug dose.

\section{REFERENCES}

1. Jannin V, Musakhanian J, Marchaud D. Approaches for the development of solid and semi-solid lipid-based formulations. Adv Drug Deliv Rev. 2008; 60: 734-746.

2. Nekkanti V, Kalepu S. Development of novel lipid based drug delivery system for Raloxifine Hydrochloride. International Research Journal of Pharmacy. 2012; 3(9): 166173.

3. Hao DC, Ge GB, Xiao PG, Wang P, Yang L. Drug metabolism and Pharmacokinetic diversity of Ranunculaceae medicinal compounds. Current Drug Metabolism. 2015; 16: 294-321.

4. Amidon G, Lennarnas H, Shah V, Crison J. A theoretical basis for a biopharmaceutics drug classification. The correlation of in-vitro drug product dissolution and in vivo bioavailability. Pharm Res. 1995; 12: 413-29.

5. Aulton M. The design and manufacture of medicin. Edn 3, Elsevier publisher of health science books and journals. 2007, pp. 320 .

6. Thomas L. Lekme, David A.Williams, Victoria F, Roche S, William Zito. Foye's principles of medicinal chemistry. 2008, pp. 75.

7. Porter CJ, Charman WN. Intestinal lymphatic drug transport: an update. Adv Drug Deliv Rev. 2001; 50(1):61-80.

8. Xu H, He L, Nie S, Guan J, Zhang X, Yang X. Optimized preparation of Vinpocetine proliposomes by a novel method and in vivo evaluation of its pharmacokinetics in New Zealand rabbits. J Control Release. 2009; 140(1): 61-8.

9. Patel J, Kevin G, Patel A, Raval M, Sheth N. Design and development of a self-nanoemulsifying drug delivery system for Telmisartan for oral drug delivery. International Journal of Pharmaceutical Investigation. 2011; 1(2): 112-118.

10. Sermkaew N, Ketjinda W, Boonme P, Phadoongsombut N, Wiwattanapatapee R. Liquid and solid self-microemulsifying drug delivery systems for improving the oral bioavailability of andrographolide from crude extract of Andrographis paniculata. European Journal of Pharmaceutical Sciences. 2013; 50(3-4):459-66.

11. Kaur G, Chandel P, Harikumar SL. Formulation Development of Self Nanoemulsifying Drug Delivery System (SNEDDS) of Celecoxib For Improvement of Oral Bioavailability. Pharmacophore. 2013; 4(4):120-133.

12. Gupta AK, Mishra DK, Mahajan SC. Preparation and in-vitro evaluation of self-emulsifying drug delivery system of antihypertensive drug, Valsartan. 2011; 2 (3): 633-639.

13. Bhikshapathi DVRN, Madhukar P, Dilip KB, Aravind KG. Formulation and characterization of Pioglitazone $\mathrm{HCl}$ selfemulsifying drug delivery system. Scholars Research Library. 2013; 5 (2): 292-305.

14. Raval C, Joshi N, Patel J, Upadhyay UM, Enhanced Oral Bioavailability of Olmesartan by using Novel Solid Self Emulsifying Drug Delivery System, International Journal of Advanced Pharmaceutics 2012; 2(2): 82-92.

15. Vanita SS, Subhashini NJP. Novel Self-Nanoemulsion Drug Delivery System of Fenofibrate with Improved BioAvailability. Int J Pharm Bio Sci. 2013. 4(2): 511-521.

16. Vijaykumar N, Zhijun W, Guru VB. Pharmacokinetic Evaluation of Improved Oral Bioavailability of Valsartan: Proliposomes versus Self-nanoemulsifying drug delivery systems. AAPS Pharm Sci Tech. 2016; 17 (4): 851-862.

17. Ruan G, Feng SS. Preparation and Characterization of Poly (lactic acid) - poly (ethylene Glycol)-poly lactic acid (PLAPEG-PLA) microspheres for the controlled release of Paclitaxel. Biomaterials. 2003; 24: 5307-44.

18. Zhongcheng $\mathrm{K}$, Xuefeng $\mathrm{H}$, Xiao-bin J. Design and optimization of self-nanoemulsifying drug delivery systems for improved bioavailability of cyclovirobuxine D. Drug Design Development and Therapy. 2016. 10: 2049-2060.

19. Lalit KT, Mohan LK. Stability Study and In-vivo Evaluation of Lornoxicam Loaded Ethyl Cellulose Microspheres. International Journal of Pharmaceutical Sciences and Drug Research, 2014; 6(1): 26-30.

20. Misra A, Shahiwala A. In-Vitro and In-Vivo Tools in Emerging Drug Delivery Scenario: Challenges and Updates. In-Vitro and In-Vivo Tools in Drug Delivery Research for Optimum Clinical Outcomes. 2018; 22: 19-42.

21. Bhatt P, Lalani R, Vhora I, Patil S, Amrutiya J, Misra A, Mashru R. Liposomes encapsulating native and cyclodextrin enclosed Paclitaxel: Enhanced loading efficiency and its pharmacokinetic evaluation. International Journal of Pharmaceutics. 2018; 536: 95-107.

22. Jinjie Zhang, Qiang Peng, sanjun shi Qiang Zhang, Xun sun, Tao gong1 Zhirong Zhang, Preparation, characterization, and in vivo evaluation of a self-nanoemulsifying drug delivery system (SNEDDS) loaded with morin-phospholipid complex. International Journal of Nanomedicine. 2011; 6: 3405- 16.

23. Veeranjaneyulu D, Aneesha A, Nandakishore Agarwal Stability Indicating RP-HPLC Method For The Simultaneous Determination of Candesartan Cilexetil And Hydrochlorothiazide In Bulk And Dosage Forms. Indian Journal of Research in Pharmacy and Biotechnology. 2011; 1(5): $720-724$

HOW TO CITE THIS ARTICLE: Venkateswara Rao J, Rama Mohan Reddy T. Self Nanoemulsifying Drug Delivery System of Candesartan Cilexetil with Improved Bioavailability. Int. J. Pharm. Sci. Drug Res. 2018; 10(5): 351-361. DOI: 10.25004/IJPSDR.2018.100501 